\title{
Is the warfarin saga over?
}

S Schulman

Professor of Medicine, Thrombosis Service, McMaster Clinic, Department. of Medicine, McMaster University, Hamilton, Ontario, Canada

This review is based on a presentation given by Professor Schulman at the RCPE Haematology Symposium on 4 November 2011.

\begin{abstract}
Warfarin is the most widely used oral anticoagulant and has been available for more than 65 years. The last decade has brought a host of new orally available anticoagulants with promising features to clinical trials and some have already been approved for limited indications. As patients are starting to be switched to these new agents there is a need to gain understanding of the subsets of patients that will benefit the most from the new alternatives and whether warfarin is still the best choice for some subpopulations. With this knowledge we will provide the individual patient with the drug that has the best benefit/risk ratio at the same time as we conserve drug expenditures. This review discusses the directions we could follow in such a tailored anticoagulation approach, referring to the limited evidence when available.
\end{abstract}

KEYWORDS Warfarin, thrombin inhibitor, management

DECLARATION OF INTERESTS Professor Schulman has received honoraria from Boehringer Ingelheim and Bayer for work in committees for the Phase III trials and revenues from a warfarin anticoagulation clinic.

\section{INTRODUCTION}

The 'warfarin saga' actually started in June 1922 with the publication of FrankW Schofield on '.... a disease in cattle simulating hemorrhagic septicaemia due to feeding sweet clover'.' The careful observations by this veterinarian (born in Rugby, England in 1889, active in Ontario, Canada; the latter half of his life devoted to helping the people of Korea, where he died in 1970) led to the isolation and crystallisation of 3,3'-methylenebis-(4 hydroxycoumarin) at the laboratory of Karl Paul Link (190|-78) at the University of Wisconsin, USA. ${ }^{2}$ The toxic substance, briefly called dicoumarol, which caused cattle to bleed to death, was entered into clinical studies in several countries; its use for preventing and treating thrombotic disease was demonstrated independently by several researchers in 1942.3-5 The delayed onset and the risk of bleeding from dicoumarol were quickly realised as well as the excellent effect it had as a rodenticide. Karl Link was apparently upset that a drug developed to treat humans was being used as a rat poison and therefore decided to synthesise another coumarinderivative intended for human use. This resulted in warfarin, named after Wisconsin Alumni Research Foundation, and patented in $1945 .{ }^{6}$

Warfarin has in numerous studies proven itself as a very effective treatment for preventing cardioembolic stroke in atrial fibrillation, ${ }^{7}$ or in patients with mechanical heart valves, ${ }^{8}$ as well as for preventing the recurrence of venous thromboembolism (VTE). ${ }^{9}$ The drawbacks are summarised in Table I. Although the quest for a more
Correspondence to S Schulman, Thrombosis Service, HHS-Genera Hospital, 237 Barton Street E., Hamilton, ON, L8L 2X2, Canada

tel. I 905527027 I, ext 44810 e-mail schulms@mcmaster.ca
TABLE I Problems associated with anticoagulation with warfarin

- Unpredictable pharmacodynamics

- 10-20-fold inter-individual difference in dose requirement

- A plethora of interactions with other drugs, certain foods, herbal remedies

- Frequent laboratory monitoring

- Risk of bleeding complications

- Need for initial overlap with a parenteral anticoagulant

- Need for bridging anticoagulation in case of surgery (at least if high thromboembolic risk)

- Patients unwilling to take 'rat poison'

predictable and convenient oral anticoagulant started several decades ago, it was only with an understanding of the tertiary molecular structure of coagulation factors and the use of $X$-ray crystallography that substances could be synthesised to suitably fit into the active-site pocket to inhibit these serine proteases. The focus was on thrombin (factor Ila) and factor Xa.

Ximelagatran, the prodrug of the reversibly binding thrombin inhibitor melagatran was first evaluated in the orthopaedic patient population, who were undergoing hip or knee replacement - a pattern followed in most other oral anticoagulant development programmes with the first results published in $2000 .^{10}$ Ximelagatran was as effective as warfarin for stroke prophylaxis in atrial fibrillation (SPAF) $)^{11,12}$ and for treatment of VTE ${ }^{13,14}$ 
but it was withdrawn from the market and all studies on February 16, 2006 due to an elevation of liver enzymes observed in up to $7 \%$ of patients and in a few cases associated with a fatal outcome. ${ }^{15}$ Since then another oral thrombin inhibitor, dabigatran (prodrug: dabigatran etexilate), has been approved for SPAF in Europe, North America and many other countries and for VTE prophylaxis in orthopaedic surgery in Europe. Among six oral factor $\mathrm{Xa}$ inhibitors currently in clinical trial, rivaroxaban has also been approved for SPAF (USA) and for VTE prophylaxis in orthopaedic surgery (Europe and many other countries). The latter indication is also approved for apixaban (Europe). Studies on the treatment of VTE with dabigatran ${ }^{16}$ or rivaroxaban ${ }^{17}$ have also been published and additional data have been presented. Rivaroxaban was recently approved in Europe and Canada for treatment for deep vein thrombosis. Will this therefore be the year of the demise of warfarin?

\section{DIFFERENCES IN EFFICACY}

Dabigatran at the higher of the two doses tested was the only drug so far that turned out to be significantly more effective than warfarin to prevent ischaemic stroke in atrial fibrillation (relative risk [RR] 0.76;95\% confidence interval [Cl], 0.60-0.98). ${ }^{18}$ Rivaroxaban was more effective than warfarin for the composite of any stroke (including haemorrhagic) and systemic embolism in the on-treatment analysis (hazard ratio [HR] 0.798; $95 \% \mathrm{Cl}$, 0.65-0.95) but not in the intention-to-treat (ITT) analysis. ${ }^{19}$ Apixaban was also more effective than warfarin for the composite endpoint of any stroke and systemic embolism (HR 0.79; 95\% Cl, 0.66-0.95) but did not reach statistical significance for ischaemic stroke. ${ }^{20}$ All three drugs appear to reduce the risk of death during the study period by approximately $20 \%$, which only reached statistical significance in the study with apixaban (HR 0.89; 95\% Cl, 0.80-0.99)..$^{20}$ Since the RRs/HRs for

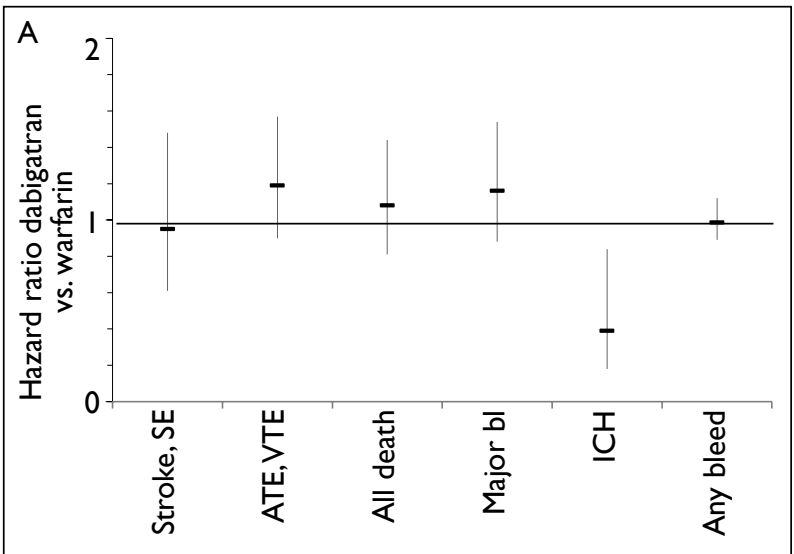

all-cause mortality are strikingly similar in the ITT analyses (dabigatran $150 \mathrm{mg}, 0.88$; dabigatran $110 \mathrm{mg}$, 0.91 ; rivaroxaban, 0.92 ; apixaban, 0.89 ) this is probably a true effect for all the drugs but it will be of interest to see what subgroup of patients this is most important for. In the studies on VTE, dabigatran and rivaroxaban have not demonstrated superiority of efficacy against warfarin. ${ }^{16,17}$

\section{PATIENTS THAT SHOULD REMAIN ON WARFARIN FOR EFFICACY}

Many patients stabilise well on warfarin after the initial period. The level of stability within the therapeutic range of the international normalised ratio (INR) is typically described as percent time in therapeutic range (TTR). This can be defined as the mean or median for the entire study population, for the individual percentages (iTTR) or for the percentages of each study centre (cTTR). Wallentin et al reported the cTTRs from the study on dabigatran in SPAF and at the centres with CTTR in the two highest quartiles $(65.5-72.6 \%$ and $>72.6 \%)$ the efficacy was similar for dabigatran $150 \mathrm{mg}$ twice daily and warfarin (Figure I). ${ }^{21}$

The argument that dabigatran is more convenient is not very relevant for this subset of patients. Warfarin is taken once daily with or without food and monitoring for the stable patients should be done every four weeks according to the American College of Chest Physicians (ACCP) guidelines ${ }^{22}$, but British guidelines have suggested up to 12-weekly monitoring. ${ }^{23}$ A retrospective British study described how some patients were successfully monitored with 14 weeks recall intervals. ${ }^{24} \mathrm{~A}$ recent randomised controlled trial with double-blind design in 250 stable patients demonstrated that 12 -weekly recall intervals were non-inferior to four-weekly intervals. ${ }^{25}$ The number of dose changes was significantly lower in the I2-weekly group. Dabigatran has to be taken twice daily,

Abbreviations: SE = systemic embolism;ATE = arterial thromboembolism;VTE = venous thromboembolism; bl = bleed; $\mathrm{ICH}=$ intracranial haemorrhage

FIGURE I Hazard ratios for important clinical outcomes with dabigatran vs warfarin in stroke prophylaxis in atrial fibrillation (SPAF) for patients at centres with (A) very good or (B) good level of anticoagulant control (>72.6\% and $65.5-$ $72.6 \%$ time in therapeutic range, respectively). Adapted from Wallentin et al. $2010 .{ }^{2}$ 
preferably with food and monitoring of the creatinine level should be done annually or, for patients with moderate renal impairment (calculated creatinine clearance 30-49 mililitres per minute $[\mathrm{mL} / \mathrm{min}])$, every six months.

\section{PATIENTS THAT SHOULD REMAIN ON WARFARIN FOR SAFETY}

Dabigatran has demonstrated improved safety regarding intracranial haemorrhage $(\mathrm{ICH}) .{ }^{18}$ The absolute reduction of risk was $0.44 \%$ per year in the Randomized Evaluation of Long-term Anticoagulation Therapy (RE-LY) study, but the risk of $\mathrm{ICH}$ in other studies on warfarin was usually approximately $0.4 \%$ and a $60 \%$ risk reduction would then correspond to an absolute risk reduction of $0.24 \%$. This can be considered in relation to the risk of major gastrointestinal bleeding. In the entire study population the RR for this event in patients treated with dabigatran $150 \mathrm{mg}$ vs warfarin was $1.36(95 \% \mathrm{Cl}, 1.09-1.70) .{ }^{18}$ In patients at centres with CTTR in the second highest and the highest quartiles, the RR was $2.26(95 \% \mathrm{Cl}, \mathrm{I} .50$ $3.40)$ and $2.00(95 \% \mathrm{Cl}, \mathrm{I} .25-3.2 \mathrm{I}){ }^{21}$ For patients at higher baseline risk of gastrointestinal bleeding due to a history of such bleeding, inflammatory bowel disease, angiodysplasia or diverticulitis this information is particularly pertinent. Whereas patients over 75 years of age still benefit from a reduced risk of intracranial bleeding, their risk of extracranial bleeding was similar or lower than with any of the doses of dabigatran. ${ }^{27}$

The increased risk of gastrointestinal bleeding on dabigatran is probably related to the high concentrations of active drug in faeces. ${ }^{28}$ There also seems to be an increase of lower gastrointestinal bleeding with rivaroxaban. ${ }^{19}$

Furthermore, there is a significant increase in the incidence and prevalence of dyspeptic symptoms (diarrhoea, nausea, heartburn, flatulence) with dabigatran, reported in 5-1 I\% of patients in the long-term treatment studies. ${ }^{16,18}$ Patients with a history of indigestion or malabsorption may be more prone to this.

\section{PATIENTS WITH RENAL FAILURE}

None of the new oral anticoagulants were given to patients with severe renal failure in the long-term treatment studies. The minimum allowed calculated creatinine clearance was $30 \mathrm{ml} / \mathrm{min}(25 \mathrm{ml} / \mathrm{min}$ for apixaban). Patients with lower creatinine clearance should not receive these drugs but patients with levels slightly above this minimum are also unsuitable since they most likely will have to switch to warfarin after a limited treatment period due to deteriorating renal function.

\section{PATIENTS WITH POOR COMPLIANCE}

It would be tempting for many physicians to switch all patients with a low TTR to a new oral anticoagulant. This would decrease time consumed with primary care staff and costs for monitoring. Some of these patients will benefit from this transition. If the reason for the low TTR is poor adherence there is no reason to believe that the patient will have better adherence to the new drug regimen, particularly if it is twice daily. On the contrary, without the frequent reminders from the anticoagulation clinic or primary care physician that the INR is low and that it is necessary to take warfarin as prescribed to avoid stroke, the patient will probably be even less compliant. The half-life of the new anticoagulants is shorter (6-17 hours) than that of warfarin (36-48 hours) and with a missed dose the patient is less protected if treated with the new anticoagulants. Thus, the poorly compliant patient will, instead of being perhaps $50-70 \%$ of the time without stroke protection on warfarin, spend $70-90 \%$ of the time unprotected. The prescribing physician will, in the absence of monitoring, not appreciate this and the first symptom of poor compliance might be a stroke.

It can sometimes be difficult to verify that a low TTR is indeed due to poor compliance, since many of those patients will not admit to it. However, the adherence to the recommended recall intervals is a good indicator.

There are other subsets of patients with a low TTR for whom simple measures could improve the quality of anticoagulation with warfarin. One example is patients with frequent infections, where the correct choice of antibiotic therapy with minimal or no interactions with warfarin is helpful. Furthermore, patients with chronic pain and intermittent use of high doses of acetaminophen that elevates the INR would benefit from a review of their pain management. Patients who misunderstand telephonic instructions regarding warfarin dose will do better when they receive written dosage instructions.

\section{PATIENTS STARTING ON ANTICOAGULANT THERAPY}

The initial period of treatment with warfarin requires weekly laboratory monitoring, sometimes even more frequently, until the individual maintenance dose has been established.This period may be deterring for both the patient and the physician and with novel agents that don't require individual adjustment it may seem obvious to prescribe one of those to all patients starting on oral anticoagulation.

Another option is to present all the important facts to the patient and have an open discussion about the best alternative, taking into account the preferences of the patient. Only for those where there is a clear indication for or contraindication against one drug should the physician make the choice. This strategy is reasonable when the evidence is weak for recommending one treatment over the other. In fact, the ACCP guidelines 
TABLE 2 Facts on warfarin and dabigatran to present to the patient

\begin{tabular}{|l|l|}
\hline Warfarin & Dabigatran \\
\hline 60 years of experience & New generation of anticoagulants \\
\hline Very effective against ischaemic stroke & $150 \mathrm{mg}$ dose generally $25 \%$ more effective \\
\hline Monitoring, initially weekly, then less frequently & Blood test for kidney function every 6-12 months \\
\hline One-third of patients become very stable & No dose changes \\
\hline Once daily & Twice daily \\
\hline Risk of intracranial bleed $0.4 \% / y e a r$ & $60 \%$ reduction of intracranial bleed risk \\
\hline Antidote available & No antidote yet, can be dialysed \\
\hline Minimal side-effects & $5-10 \%$ complain of dyspepsia \\
\hline $\begin{array}{l}\text { "Adapted for the patient eligible for the higher dose of I50 mg dabigatran twice daily. For those with moderate renal } \\
\text { dysfunction there is no increase of effect against stroke but there is a reduction of all types of bleeding except gastrointestinal. }\end{array}$
\end{tabular}

recognise the importance of patient preferences ${ }^{29}$ and this will play an even more important role in the ninth edition that will be published in 2012. The facts that would be important to present to the patients are shown in Table 2.

\section{FORESEEABLE CHANGES IN THE DECISION PROCESS}

Of the factor $\mathrm{Xa}$ inhibitors, rivaroxaban has recently been widely approved for the SPAF indication and apixaban is likely to achieve this in the near future. Their characteristics are slightly different from dabigatran and the facts presented to the patients will have to be modified accordingly. Both might be reversed by prothrombin complex concentrates ${ }^{30}$ and they have not been associated with dyspepsia. Rivaroxaban is taken once daily. There was no significant reduction of ischaemic stroke with either drug. Apixaban was associated with a reduced risk for any major bleeding (in addition to reduced risk for $\mathrm{ICH}) .^{20}$

A humanised monoclonal antibody is being developed for rapid neutralisation of dabigatran ${ }^{31}$ and may reach approval for marketing in two years.

As the experience with these novel anticoagulants accumulates and competition possibly brings the drug acquisition cost down, a broader transition from warfarin can be anticipated and will be justified.The first trial with a new oral anticoagulant (dabigatran) for patients with mechanical heart valves started recruitment in October $20 \mathrm{II}^{32}$ and it is hoped the drug will be found suitable for these patients as well. However, until the appropriate studies have been performed it is hazardous to prescribe off-label any of the new anticoagulants to patients with mechanical valves. The required dose is unknown and might differ from the regimen used in SPAF. An indirect factor $\mathrm{Xa}$ inhibitor, fondaparinux, was associated with an increased risk of catheter-related thrombosis in patients with acute coronary syndromes undergoing heart catheterisation. ${ }^{33}$ It is possible that contact activation of the coagulation system requires a broader inhibition.
Few patients with VTE and active cancer or antiphospholipid syndrome have been included in the trials. Until more experience has been gained regarding these subgroups it is advisable to use long-term anticoagulation with low-molecular-weight heparin, particularly in case of warfarin failure.

\section{COST OF ANTICOAGULATION}

The monthly cost of dabigatran in Canada is, together with the dispensing fee, \$CAD 130, but it is approximately double in the United States and vastly higher than the cost of warfarin anywhere. However, the true cost of warfarin, when including monitoring, indirect costs (patient travel to laboratory, caregiver support) and adverse events becomes progressively much higher. The total cost for warfarin therapy varies widely between different published assessments. Complicating the picture further, health economy studies of dabigatran have shown effects in opposite directions and the price of rivaroxaban or apixaban may differ from that of dabigatran.

\section{CONCLUSION}

There are several subgroups of patients currently being treated with warfarin where there is no clear benefit from switching to dabigatran. These include patients who are very stable on warfarin, patients with gastrointestinal disorders and/or increased risk for gastrointestinal haemorrhage, those with a creatinine clearance approaching $30 \mathrm{ml} / \mathrm{min}$ and patients with a record of poor compliance. The majority of patients about to start on anticoagulation for SPAF should be able to make an informed choice of drug. Personal experience has shown that among patients for whom cost or reimbursement is not an issue, almost equal proportions choose warfarin or dabigatran. This will surely change with increasing experience from the new drugs, including the management of bleeding complications. The warfarin saga is not over - yet. 


\section{REFERENCES}

I Schofield FW. A brief account of a disease in cattle simulating hemorrhagic septicemia due to feeding sweet clover. Can Vet Rec 1922; 3:74-8.

2 Link KP. The anticoagulant from spoiled sweet clover hay. Harvey Lect 1943-44; 39: 162-216.

3 Allen EV, Barker NW, Waugh JM. A preparation from spoiled sweet clover (3,3'-methylene-bis-[4-hydroxycoumarin]) which prolongs coagulation and prothrombin time of the blood: a clinical study.JAMA 1942; 120:1009-15. http://dx.doi.org/10.1001/ jama.1942.028304800I3004

4 Butsch WC, Stewart JD. Clinical experiences with dicoumarin, 3,3'-methylene-bis-(4-hydroxycoumarin). JAMA 1942; 120:1025-6. http://dx.doi.org//0.1001/jama.1942.02830480029007

5 Lehmann J. Hypoprothrombinaemia produced by methylene-bis(hydroxycoumarin), its use in thrombosis. Lancet 1942; I:318. http://dx.doi.org/I0.10I6/S0I40-6736(00)57768-X

6 Link KP. The discovery of dicumarol and its sequels. Circulation 1959; 19:97-107.

7 Singer DE, Albers GW, Dalen JE et al. Antithrombotic therapy in atrial fibrillation: the Seventh ACCP Conference on Antithrombotic and Thrombolytic Therapy. Chest 2004; I26:429S-56S. http://dx.doi. org/10.1378/chest.126.3_suppl.429S

8 Salem DN, O'Gara PT, Madias C et al. Valvular and structural heart disease: American College of Chest Physicians evidencebased clinical practice guidelines (8th Edition). Chest 2008; I 33:593S-629S. http://dx.doi.org/10.1378/chest.08-0724

9 Kearon C, Kahn SR, Agnelli G et al. Antithrombotic therapy for venous thromboembolic disease: American College of Chest Physicians evidence-based clinical practice guidelines (8th Edition) Chest 2008; I 33:454S-545S. http://dx.doi.org/ 10.1378/chest.08-0658

10 Eriksson BI, Lindbratt S, Kälebo P et al. METHRO II: Doseresponse study of the novel oral direct thrombin inhibitor $\mathrm{H} 376 / 95$ and its subcutaneous formulation melagatran, compared with dalteparin as thromboembolic prophylaxis after total hip or total knee replacement. Haemostasis 2000; 30:20-I.

II Olsson SB. Stroke prevention with the oral direct thrombin inhibitor ximelagatran compared with warfarin in patients with non-valvular atrial fibrillation (SPORTIF III): randomised controlled trial. Lancet 2003; 362:169I-8. http://dx.doi.org/I0.1016/SOI406736(03)|484|-6

12 The Executive Steering Committee on behalf of the SPORTIF V Investigators. Stroke prevention using the oral direct thrombin inhibitor ximelagatran in patients with non-valvular atrial fibrillation (SPORTIFV). Circulation 2003; 108:2723.

I3 Fiessinger JN, Huisman MV, Davidson BL et al. Ximelagatran vs low-molecular-weight heparin and warfarin for the treatment of deep vein thrombosis: a randomized trial. JAMA 2005; 293:68I-9. http://dx.doi.org/I0.100I/jama.293.6.68I

14 Schulman S,Wahlander K, Lundstrom T et al. Secondary prevention of venous thromboembolism with the oral direct thrombin inhibitor ximelagatran. N Engl J Med 2003; 349:I713-2I. http:// dx.doi.org/I0.1056/NEJMoa030I04

I5 Ho SJ, Brighton TA. Ximelagatran: direct thrombin inhibitor. Vasc Health Risk Manag 2006; 2:49-58. http://dx.doi.org/I0.2I47/ vhrm.2006.2.I.49

16 Schulman S, Kearon C, Kakkar AK et al. Dabigatran versus warfarin in the treatment of acute venous thromboembolism. N Engl J Med 2009; 36I:2342-52. http://dx.doi.org/I0.I056/NEJMoa0906598

17 Bauersachs R, Berkowitz SD, Brenner B et al. Oral rivaroxaban for symptomatic venous thromboembolism. N Engl J Med 2010; 363:2499-5 10. http://dx.doi.org/I0.1056/NEJMoal007903

18 Connolly SJ, Ezekowitz MD, Yusuf S et al. Dabigatran versus warfarin in patients with atrial fibrillation. N Engl J Med 2009; 36I:I|39-5I. http://dx.doi.org/I0.I056/NEJMoa090556 |
19 Patel MR, Mahaffey KW, Garg J et al. Rivaroxaban versus warfarin in nonvalvular atrial fibrillation. $N$ Engl J Med 20I I; 365:883-9l. http://dx.doi.org/I0.I056/NEJMoal 009638

20 Granger CB, Alexander JH, McMurray JJ et al. Apixaban versus warfarin in patients with atrial fibrillation. $N$ Engl J Med 20II; 365:98I-92. http://dx.doi.org// 0.1056/NEJMoa I I07039

21 Wallentin L, Yusuf S, Ezekowitz MD et al. Efficacy and safety of dabigatran compared with warfarin at different levels of international normalised ratio control for stroke prevention in atrial fibrillation: an analysis of the RE-LY trial. Lancet 20I0; 376:975-83. http://dx.doi. org/I0.1016/S0140-6736(10)6II94-4

22 Ansell J, Hirsh J, Hylek E et al. Pharmacology and management of the vitamin $\mathrm{K}$ antagonists: American College of Chest Physicians evidence-based clinical practice guidelines (8th Edition). Chest 2008; I33:I60S-198S. http://dx.doi.org/I0.1378/chest.08-0670

23 [No authors listed]. Guidelines on oral anticoagulation: third edition. Br J Haematol 1998; I0 I:374-87. http://dx.doi.org/ I0.1046/ i.I365-2I4I.1998.007I5.x

24 Lidstone V, Janes S, Stross P. INR: Intervals of measurement can safely extend to I4 weeks. Clin Lab Haematol 2000; 22:29I-3. http://dx.doi.org/I0.1046/j.I365-2257.2000.003I5.x

25 Schulman S, Parpia S, Stewart $C$ et al. Warfarin dose assessment every 4 weeks versus every 12 weeks in patients with stable international normalized ratios: a randomized trial. Ann Intern Med 20II; 155:653-9.

26 Schulman S, Beyth RJ, Kearon C et al. Hemorrhagic complications of anticoagulant and thrombolytic treatment:American College of Chest Physicians evidence-based clinical practice guidelines (8th Edition). Chest 2008; 133:257S-298S. http://dx.doi.org/10.1378/ chest.08-0674

27 Eikelboom JW,Wallentin L, Connolly SJ et al. Risk of bleeding with 2 doses of dabigatran compared with warfarin in older and younger patients with atrial fibrillation: an analysis of the Randomized Evaluation of Long-term anticoagulant therapY (RELY) trial. Circulation 20I I; I23:2363-72. http://dx.doi.org/I0.II6I/ CIRCULATIONAHA.I 10.004747

28 Blech S, Ebner T, Ludwig-Schwellinger E et al. The metabolism and disposition of the oral direct thrombin inhibitor, dabigatran, in humans. Drug Metab Dispos 2008; 36:386-99. http://dx.doi. org/I0.1 I24/dmd.107.019083

29 Schunemann HJ, Cook D, Guyatt G. Methodology for antithrombotic and thrombolytic therapy guideline development:American College of Chest Physicians Evidence-based Clinical Practice Guidelines (8th Edition). Chest 2008; 133:II3S-122S. Erratum in: Chest 2008; 134:473. http://dx.doi.org//0.1378/chest.08-0666

30 Eerenberg ES, Kamphuisen PW, Sijpkens MK et al. Reversal of rivaroxaban and dabigatran by prothrombin complex concentrate: a randomized, placebo-controlled, crossover study in healthy subjects. Circulation 20II; I24:I573-9. http://dx.doi.org//0.1/6I/ CIRCULATIONAHA.III.0290I7

31 Van Ryn J, Litzenberger T, Waterman A et al. Dabigatran anticoagulant activity is neutralized by an antibody selective to dabigatran in in vitro and in in vivo models. J Am Coll Cardiol 201 I; 57:EI I30. http://dx.doi.org/I0.1016/S0735-1097(II)6II30-3

32 ClinicalTrials.gov [Internet].c20I I. Dabigatran etexilate in patients with mechanical heart valves. (NCTOI452347) [updated 2012 Feb 8; cited 20I2 Feb 10]. Available from: http://clinicaltrials.gov/ct2/ show/NCT0I452347

33 Yusuf S, Mehta SR, Chrolavicius S et al. Comparison of fondaparinux and enoxaparin in acute coronary syndromes. N Engl J Med 2006; 354: | 464-76. http://dx.doi.org//0.1056/NEJMoa055443 